\title{
Harm minimisation in a school zone: a strategy for sustaining pedestrian safety
}

\author{
Z. Ebrahim \& H. Nikraz \\ Department of Civil Engineering, Curtin University, Australia
}

\begin{abstract}
In an endeavour to achieve high, Australia has directed its attention to the Towards Zero strategy that involves aiming for no fatalities on the road. Road crashes are costing Australia $\$ 18$ billion every year. This paper highlights the sustainability benefits of the $40 \mathrm{~km} / \mathrm{h}$ school zone that has provided safer roads, higher savings and socially pleasant environments. It examines why school zone drivers are prompted to slow down and elsewhere they are not. They are the same drivers, but on different segments of the road network. This safe driving behaviour needs to be shifted to roads outside the school zones. A comparative analysis of the recent enforcement data has focused on two detection types, the 'On the spot' and 'roadside'. Results show that two domains need to be continuously proactive: the no fatality approach and the harm minimisation approach (minor injuries rather than severe). The paper focuses on changing the detection type according to the environment of the zone. This is considered as the ultimate unfailing planning enforcement support. From an engineering view point, the remarkable flashing $40 \mathrm{~km} / \mathrm{h}$ limit signs may have proven to be of impressive benefits in terms of drivers obeying the speed limit. The signs are bright and clear and most of all alerting as they flash, causing fast drivers to observe them and adjust their speed. It is concluded that the aim of achieving sustainability is to manage and monitor the maximum benefits of the trade-off between the diminishing returns in achieving highest harm minimisation and a police presence between school and non-school zones.
\end{abstract}

Keywords: school zone, roadside, on the spot, TINs, sustainability. 


\section{Introduction}

It is well documented globally that lower speed can prevent crashes, reduce severities and most importantly save pedestrian lives [1]. The OECD considered that enforcement is a difficult task as speeding remains the most wide spread offence [2]. The school zone is one area that authorities in Australia have focused their attention on to enforce speed limits. They are targeting speedsters to protect pedestrians by minimising harm. This harm comes from the substantial severe injuries that could face pedestrians in a crash compared to other road users. In the metropolitan city of Perth, Western Australia, a $40 \mathrm{~km} / \mathrm{h}$ zone is used around schools with electronically solar powered signs that display a white 40 with a flashing red ring around it. This is applicable for school days 7:30-9:00 am and 2:30-4:00 pm.

According to the office of road safety for $34 \%$ of fatal crashes speed has a contributing factor. Therefore lowering speed limits has been the initiatives of authorities all over Australia. For instance, a review of international speed limits (compared to other OECD countries) found that Australia's limits tended to be higher than those found elsewhere, including those in Europe and North America [3]. They recommended that to reduce road injuries further, more must be done to reduce driving speeds in Australia, and lowering speed limits may be a critical component in achieving this outcome. The Austroads report revealed that EU countries have utilized harm minimization principles as the basis for setting speed limits. The necessity of speed limits is well documented in [4]. Most recent information from the office of road safety shows that there is a far bigger problem in Perth, involving thousands of "good" drivers who took frequent smaller risks such as low-level speeding [5]. In terms of school zones and according to [6], there was a drop of $28 \%$ in TINs for speedsters between 2010 and 2011.

A study in [7] compared Australian 40km/h school zone fatalities and found that the Malaysian school zone speed enforcement policy was far behind the Australian policy despite similar engineering measures adopted in and around school zones. The study findings attributed the success to the higher level of enforcement in Australia in reducing road crashes. It has been demonstrated in [8] that the more enforcement, the greater the reduction in the number of crashes.

The crash trends in Figure 1 indicate that most of the pedestrian crashes are lowered in Perth, but it seems in the last 20 years the trend for the younger group of 2-16 years are steeper than the rest of the age groups. For the urban area under study, there were no fatalities and only three serious injuries during the period July 2009 to June 2011 for this age group involving school zones. In general, this age group is involved mainly within school zones.

Therefore the aim of this paper is to target drivers who exceed the speed limit around school and non-school zones. It focuses on TINs and compares the monthly rate per hour for the TINs of both school and non-school zones. Two detection types were used similar to those adopted in other major cities in Australia. The first type is the road side camera placed inside a vehicle or on the ground, both of which will be detecting from the side of the road: these will be 
referred to as 'road side' detection. The second type is the on the spot detection which involves all instances where a vehicle is pulled over, including marked/unmarked cars and hand-held detectors, which will be referred to as 'on the spot' detection.

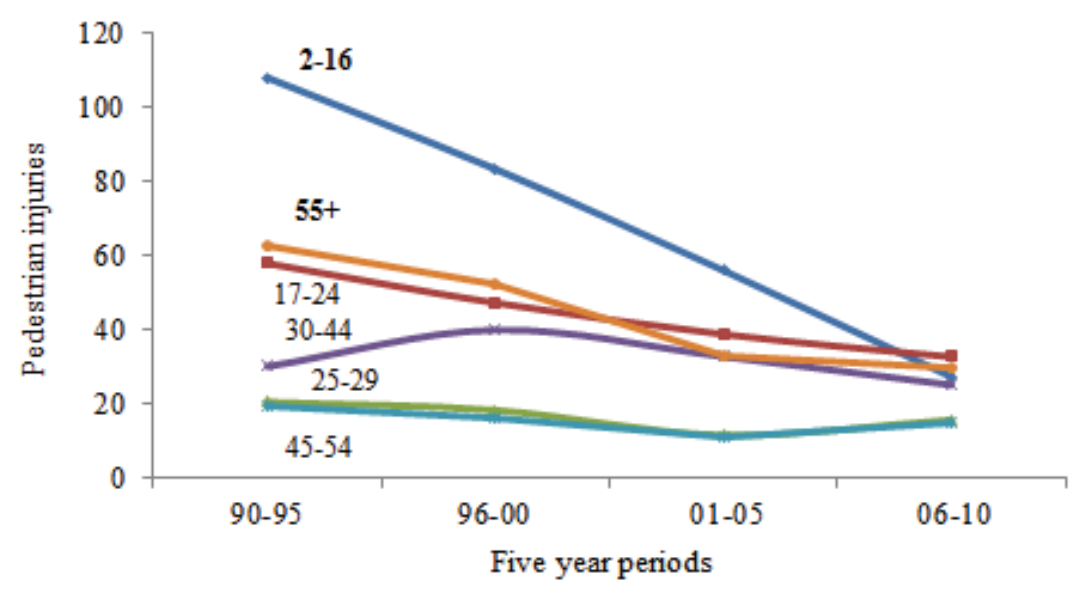

Figure 1: The youngest pedestrian age group of crashes is sharply decreasing compared to the other five age groups.

\section{Enforcement of school vs. non-school zones}

\subsection{TINs hourly rate per month}

The study covers 165 suburbs of the urban area of Perth. The enforcement data was (74498) TINs for the period July 2007 to June 2011. It examined school zone vs. non-school zones. The data for comparing 'road side' and 'on the spot' TINs was limited to (47119) TINs for the period July 2009 to June 2011. This is due to the unavailability of TINs for the roadside detection type of the $40 \mathrm{~km} / \mathrm{h}$ non-school zones. In this section, the rate of the monthly TINs per hour rate was calculated for both zones and for the two detection types. This was collated by converting each deployment of each suburb to hours. The calculation involved the date and time of the incident of each single deployment.

In using the roadside detection comparative rates of school and non-school zones, two observations can be observed from Figure 2. Firstly, the rate of detection (TINs/h) around school zones is lower than that around non-school zones. It shows that if the detection rate around school zones continues as it is now, it will continue to increase; hence this may suggest that this increase in using these roadside cameras might be effective in detecting higher numbers of local speeding drivers. It may eventually be lowered once the specific deterrence increases leading to a higher level of general deterrence. On the other hand, it may be argued that school zones do differ from other $40 \mathrm{~km} / \mathrm{h}$ zones. The former tend to service local commuters including parents of the students, unlike the nonschool zones that service local and non-local drivers. These roads generally exist in and around the CBD (Central Business District) of Perth. Observations by 
authors around the school zones showed that many drivers around school zones are complying and are more cautious around schools when it comes to speeding. It is paramount to mention that some drivers from a few suburbs are driving outside the safety norm than other drivers from other suburbs.

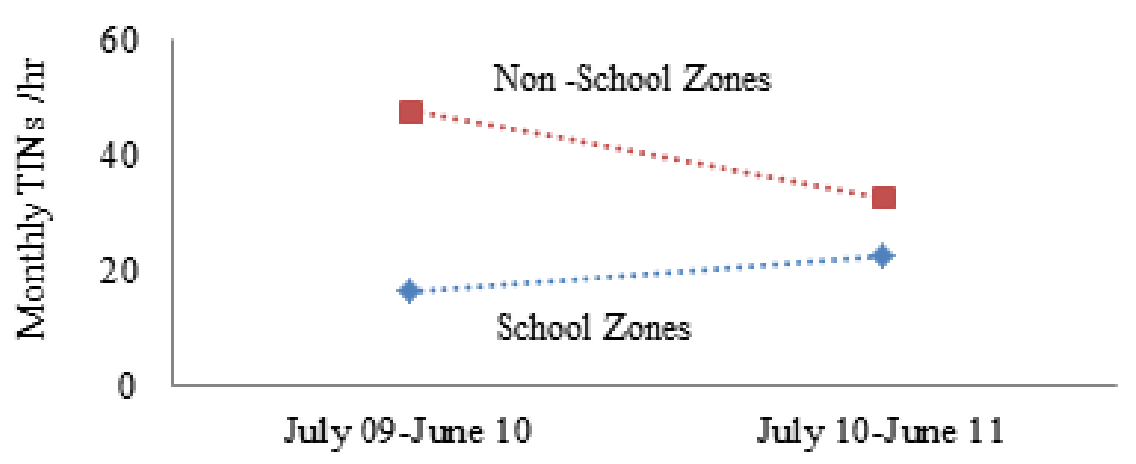

Figure 2: $\quad$ The roadside speed camera detection of both zone types.

Secondly Figure 2 reveals that the detection rate of TINs/h around the nonschool zones is becoming lower, but is still higher than those detection rates around school zones. It may be that the period between July 2009 and June 2010, was the start of the non-school zone introduction of the $40 \mathrm{~km} / \mathrm{h}$ speed limits and drivers showed less compliance at the beginning as the high TINs rate indicates. In addition to that, it may be caused by the familiarity with camera locations as [9] has suggested.

The other important part of this comparative rate of TINs is using the "on the spot" detection type which showed a stable rate of TINs detected around school zones. However, the detection rates around the non-school zones are on the increase and may need more coercive planning, see Figure 3. This may be because of the familiarity of drivers with the location where police officers stand and because of the limited appropriate locations.

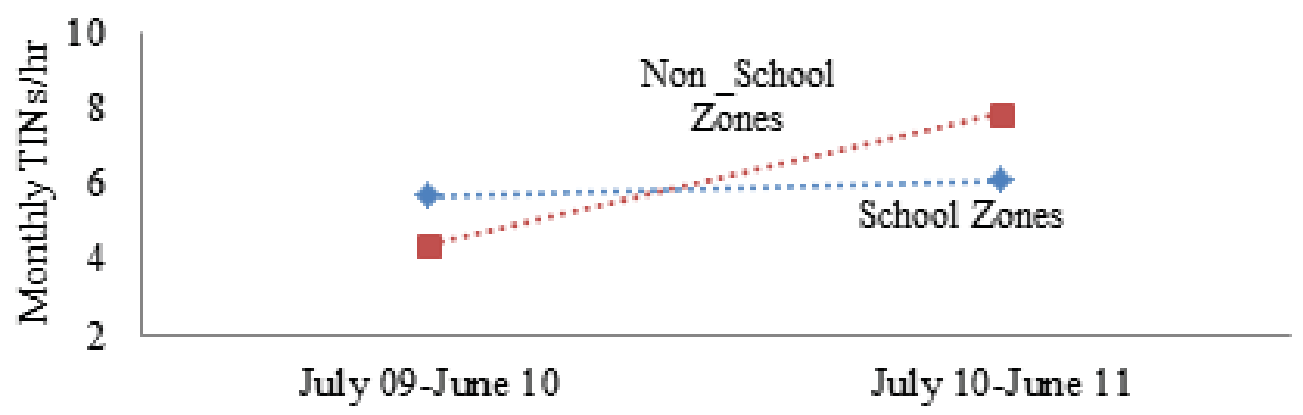

Figure 3: The on the spot camera detection of both zone types.

From a sustainability view point, it is suggested that some of the coercive efforts need to enhance more 'roadside' camera hours around school zones and sustain more 'on the spot' hours around non-school zones. This is suggested for two reasons. 
Firstly the $40 \mathrm{~km} / \mathrm{h}$ is a fairly a new idea around non-school zones and when using 'on the spot' detection, it is more difficult to notice a police officer around a busy shopping area or even in a roadwork's zone. This is more pronounced in the evening or during the weekend where more vulnerable pedestrian movement exists around entertainment areas. This type of detection may generally deter drivers from speeding around non-school zones and by intensifying the hours or managing more randomised scheduling as indicated by [10] this may broaden the general effect. The 'on the spot' type would activate harm minimisation by detecting drivers with higher levels of speeding. This is discussed in the next section.

Secondly, from a sustainability view point, it is suggested that roadside camera hours are increased around school zones so as to still detect drivers exceeding the speed limit. The fitted curves to the roadside TINs data form school zones in Figure 4 show a reserved capacity for detecting more TINs before reaching a diminishing return or a decay.

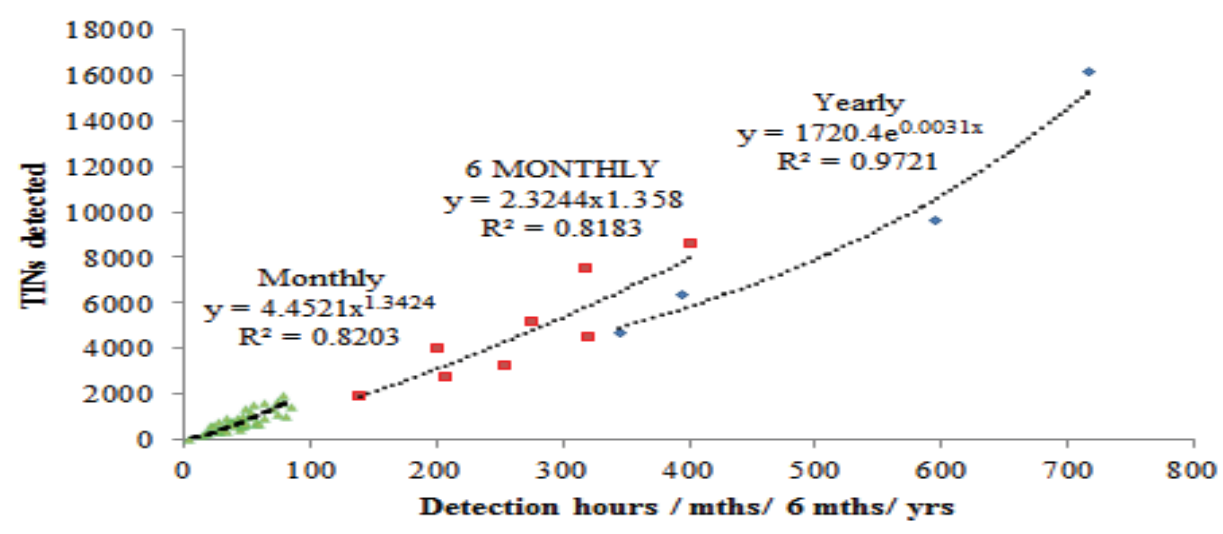

$\mathrm{BHH}$

Figure 4: The roadside detection data around school zones fitted to different functional curves.

\subsection{TINs on different speed levels}

This section focuses on the importance of the 'on the spot' type in detecting higher level speeding and excessive speed. See Figure 5.

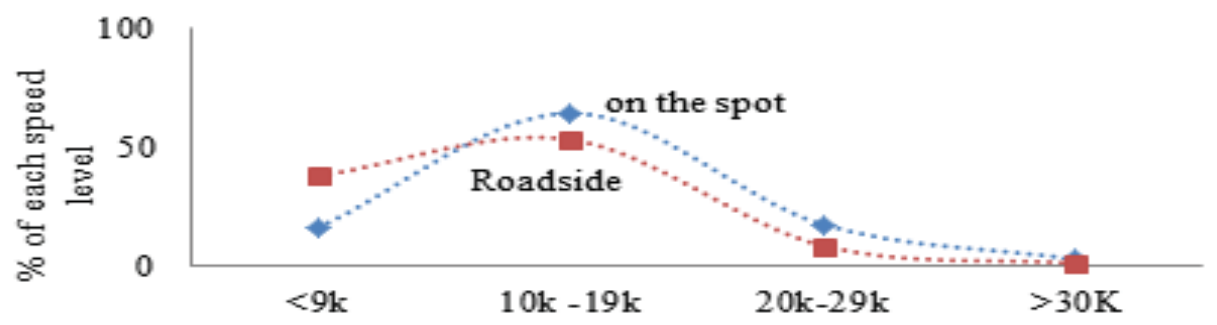

Figure 5: The dominance of the on the spot in detecting higher excessive speed around all the $40 \mathrm{~km} / \mathrm{h}$ roads. 
The use of the 'on the spot' type demonstrated its dominance in detecting higher speed violations. It also reveals that roadside type detects a higher number of TINs that involves mainly the lowest level of speeding which is less than $9 \mathrm{~km} / \mathrm{h}$ over the speed limit. This may need to be addressed as was found in [11] and [12].

Another way of looking into the dominance of the 'on the spot' detection is using the ratio of 'on the spot' over the roadside type as shown in Figure 6. It shows that both curves are increasing as the speed offence level is increasing. This may also explain the lack of detection of higher speed by the roadside cameras. It may not only be familiarity with the location. It may be that drivers are able to slow down before facing the roadside camera. This may be difficult to do when approaching a police officer at such high speed. The 'on the spot' detection has also shown to record higher numbers of TINs in general in particular locations and may contribute strongly to the harm minimisation process in terms of offence numbers and excessive speed. It may therefore contribute strongly to the reduction of pedestrian fatalities including serious injuries.

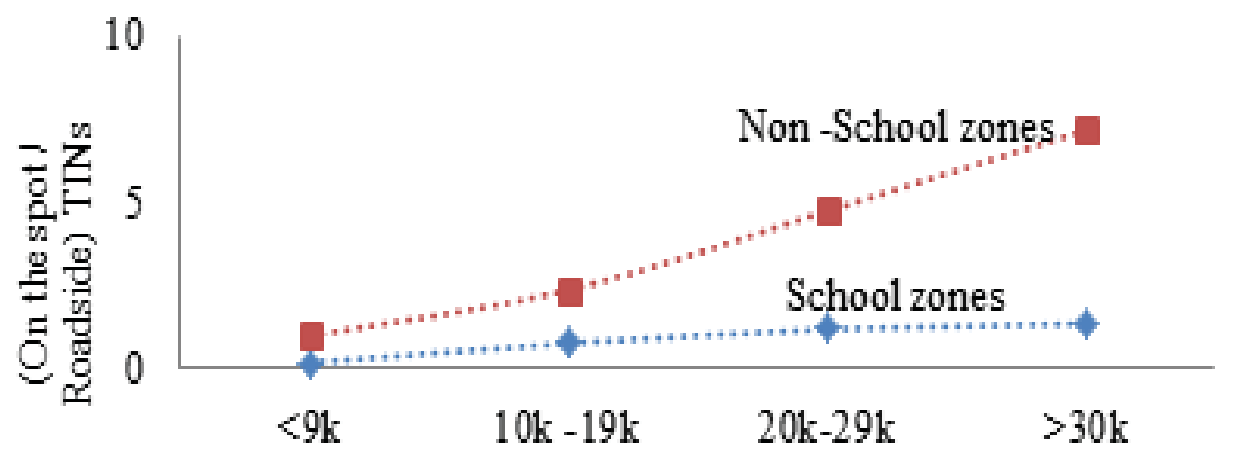

Figure 6: The strength of the on spot detection of offenders with higher speed.

Eventually it is vital to expose the tangible importance of the presence of police officers on the road and not to rely solely on just cameras on the road like suggested by [13], as the presence of police officers is desired by the community.

\section{Discussions}

The sustainability of enforcing a change in risky behaviour towards safer road use is essential. Targeting more speeders around school zones and detecting higher and excessive speed around non-school zones are also very vital. This paper is suggesting a trade-off between the benefit of utilising more detection on roadside types around school zones and an increase in the hours of the enhanced speed enforcement program around non-school zones. From a social cultural point of view, the paper is also suggesting that use is made of the positive compliance of the good driving culture around school zones by directing this good action into good news in the media rather than leaving the media to inform 
the public of how high the TINs are. Therefore it is essential to educate the media about the positive aspects that are coming from a suburb (s) or certain age group and parents that may contribute towards such sustainability. It is believed that the media can play a vital role in encouraging more compliance and spreading a safe feeling amongst community members. See the illustration in Figure 7.

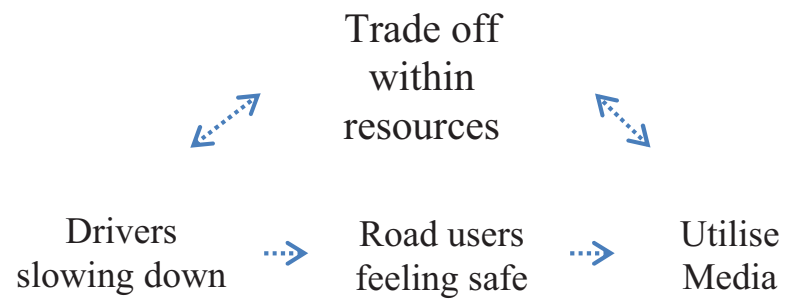

Figure 7: Sustainability towards zero pedestrian fatalities.

\section{Conclusions}

It is known in the global road safety literature that speed enforcement involves complex perpetual behavioural issues of road users, stretches from legislation, laws and non-compliance by offenders. Therefore politicians and the public may need to support such a socio-political decision for the benefit of reducing harm, increasing resources and conveying a good positive message.

\section{Acknowledgements}

We would like to thank Chris Canny the Assistant Director of the Academic Development of the WA Police for her valuable support and acknowledgement of this paper. Thanks also go to the Academic Research Administration Unit of the WA police for supplying the data and clarifying labelling and other data inquiries.

\section{References}

[1] World Health Organisation (WHO). Speed management: a road safety manual for decision-makers and practitioners, Geneva, Global Road Safety Partnership, 2008.

[2] ETSC - European Transport Safety Council, Managing Speed towards Safe and Sustainable Road Transport, pp 1-34, 2008.

[3] Austroads, Balance between harm reduction and mobility in setting speed limits: A feasibility study. Report no. AP-R 272/05, 2005.

[4] Elvik, R., The Power Model of the relationship between speed and road safety. Institute of Transport Economics. Oslo, Report no. 1034/2009.

[5] Holman, D. 'Good' drivers a danger. The Weekend West Australian, May 14, pp 1-3, 2011. 
[6] Knowles, G. and Eliot, L., Drivers urged to slow down as schools reopened. West Australian, 2 February 2012.

[7] Abdul Hanan, S., King, M. J. and Lewis, I. M., Understanding speeding in school zones in Malaysia and Australia using an extended Theory of Planned Behaviour: the potential role of mindfulness, Journal of the Australasian College of Road Safety, 22(2), pp. 56-62, 2011.

[8] Elvik, R.., cost-benefit analysis of police enforcement. Implications of choice of framework for Cost-Benefit Analysis of Police enforcement, pp. 1-75, 2001.

[9] Carnis, L. and Rakotonirainy, A. and Fleiter, Judy J. Speed enforcement programmes in France and Queensland: First elements for a systematic comparison. Proc. of National Conference of the Australasian College of Road Safety and the Travel safe Committee of the Queensland Parliament, Brisbane, pp. 40-53, 2008.

[10] Cameron, M., safety benefits of speed cameras. Fact sheet no. 5. Curtin Monash Accident Research Centre. pp. 1-9, 2009.

[11] Doecke, S.D., Kloeden, C.N., McLean, A.J. (2011). Casualty crash reductions from reducing various levels of speeding. Centre for Automotive Safety Research CASR076. Adelaide, Australia.

[12] Gavin, A., Walker, E., Murdoch, C., Graham, A., Fernandes, R., Job, R.F.S Is a focus on low level speeding justified? Objective determination of the relative contributions of low and high level speeding to the road toll. Proceedings of the Australasian Road Safety, Research, Policing and Education Conference, Canberra, Australia. (2010).

[13] Goldman, T. Gorham, R., Sustainable urban transport: Four innovative directions, Technology in Society 28, pp. 261-273, 2006. 